\title{
O protagonismo feminino no parto domiciliar: Relatos de experiências
}

\section{Female protagonism in home birth: Reports of experiences \\ Female protagonism in home birth: Reports of experiences}

Danielle Carvalho Rocha

ORCID: https://orcid.org/0000-0002-4022-037X

Universidade Estadual do Maranhão, Brasil

E-mail: daniellerocha.slz@gmail.com

Kaio Germano Sousa da Silva

ORCID: https://orcid.org/0000-0003-4236-6230

Centro Universitário de Ciências e Tecnologia do Maranhão, Brasil

E-mail: kaiogsds@hotmail.com

Luana Pereira Ibiapina Coêlho

ORCID: https://orcid.org/0000-0002-2054-959X

Faculdade de Venda Nova do Imigrante, Brasil

E-mail: luana_ibiapina@hotmail.com

Milka Borges da Silva

ORCID: https://orcid.org/0000-0002-3704-255X

Universidade Estadual do Maranhão, Brasil

E-mail: mylkaborges@ hotmail.com

Polyana Cabral da Silva

ORCID: https://orcid.org/0000-0003-2626-5181

Universidade Estadual do Maranhão, Brasil

E-mail: enf.polyanacabral@ hotmail.com

Mickaelle Bezerra Calaça

ORCID: https://orcid.org/0000-0001-9872-6675

Universidade Estadual do Maranhão, Brasil

E-mail: mickaellebezerra@outlook.com

Luzivania de Jesus Oliveira

ORCID: https://orcid.org/0000-0002-4365-1407 Faculdade Laboro, Brasil

E-mail: 1uhdj_12@hotmail.com

Sostenise Maciel de Azevedo

ORCID: https://orcid.org/0000-0002-4731-8337

Universidade Estadual do Maranhão, Brasil

E-mail: sostenisemaciel@gmail.com

Ana Carolina Feitosa Chaves

ORCID: https://orcos.org/0000-0002-0309-5354

Universidade Estadual do Maranhão, Brasil

E-mail: ac.feitosa@outlook.com

Jesica Cristina Lira dos Santos

ORCID: https://orcid.org/0000-0003-1902-585X

Universidade Estadual do Maranhão, Brasil

E-mail: jecristinalira@gmail.com

Eduardo Brito da Silva

ORCID: https://orcid.org/0000-0002-8571-7806 Centro Universitário de Ciências e Tecnologia do Maranhão, Brasil

E-mail: eduzinhobds@gmail.com

Pedro Henrique Medeiros de Andrade

ORCID: https://orcid.org/0000-0003-1819-9540

Centro Universitário de Ciências e Tecnologia do Maranhão, Brasil

E-mail: pedro.medeiroscx@gmail.com

Maria Isabelly Reis Teixeira

ORCID: https://orcid.org/0000-0002-8177-4379

Universidade Federal do Piauí, Brasil

E-mail: maria-belly@hotmail.com

Pedro Vitor Mendes Santos

ORCID: https://orcid.org/0000-0002-2249-1440

Universidade Estadual do Maranhão, Brasil

E-mail: pedrovitorp2@hotmail.com

Ana Carolina Rodrigues da Silva

ORCID: https://orcid.org/0000-0003-4562-7088

Universidade Federal do Piauí, Brasil

E-mail: enf.carolinarodrigues@hotmail.com 


\title{
Resumo
}

Este trabalho tem como objetivo conhecer a experiência das mulheres que tiveram parto no âmbito domiciliar, nos municípios de São Luís, e São José de Ribamar, do estado do Maranhão. Trata-se de uma pesquisa exploratória, descritiva, com abordagem qualitativa, com a participação de 9 mulheres, sendo as entrevistas realizadas nos meses de setembro e outubro de 2017. Para análise dos dados, utilizou-se a técnica de análise de conteúdo de Bardin. Dos resultados emergiram três categorias temáticas. 1- Motivadores para a vivência do parto domiciliar; 2- As visões diante do parto domiciliar; 3- Emersão de sentimentos com a vivência do parto em casa. As entrevistas mostraram que o desejo por autonomia, o respeito, pelo protagonismo, a elevada renda familiar e nível de escolaridade, foram pontos decisivos para vivência do parto domiciliar, assim como o respaldo das consultas de pré-natal. Com isso, foi possível concluir que o parto domiciliar configura-se atualmente como um confrontamento ao que é oferecido pelos sistemas de saúde, público ou de âmbito particular, emergindo de uma necessidade de vivenciar de forma visceral a fisiologia do corpo feminino. O protagonismo dessa nova escolha de parir, evidenciou o desejo de se sentirem ativas em seus partos.

Palavras-chave: Humanização; Parto domiciliar; Protagonismo; Enfermagem; Nascimento.

\begin{abstract}
This study aims to know the experience of women who had a home birth in the cities of São Luís, and São José de Ribamar, in the state of Maranhão. This is an exploratory, descriptive study with a qualitative approach, with the participation of 9 women and the interviews were carried out from September to October 2017. For the data analysis, we used the Bardin content analysis technique. From the results three thematic categories emerged. 1- Motivators for the experience of home birth; 2- The visions of the home birth; 3- Emmersion of feelings with the experience of home birth. The interviews showed that the desire for autonomy, respect, protagonism, high family income and education level were decisive points for the experience of home birth, as well as the support of prenatal consultations. Thus, it was possible to conclude that home delivery is nowadays a confrontation with what is offered by public or private health systems, emerging from a need to viscerally experience the physiology of the female body. The protagonism of this new birth choice evidenced the desire to feel active in their births.
\end{abstract}

Keywords: Humanization; Home birth; Protagonism; Nursing; Birth.

\begin{abstract}
Resumen
Este trabajo tiene como objetivo conocer la experiencia de las mujeres que han dado a luz en casa, en los municipios de São Luís, São José de Ribamar, Raposa y Paço do lumiar, en el estado de Maranhão. Se trata de una investigación exploratoria, descriptiva, con enfoque cualitativo, con la participación de 9 mujeres, y las entrevistas se realizaron en los meses de septiembre y octubre de 2017. Para el análisis de datos se utilizó la técnica de análisis de contenido de Bardin. De los resultados surgieron tres categorías temáticas. 1- Motivadores para la experiencia del parto en casa; 2Visiones sobre el parto en casa; 3- Emersión de sentimientos con la experiencia del parto en casa. Las entrevistas mostraron que el deseo de autonomía, respeto, protagonismo, altos ingresos familiares y nivel educativo, fueron puntos decisivos para vivir el parto en casa, así como el apoyo de las consultas prenatales. Con esto, se pudo concluir que el parto domiciliario se configura actualmente como un enfrentamiento a lo que ofrecen los sistemas de salud, públicos o privados, surgiendo de una necesidad de experimentar visceralmente la físiología del cuerpo femenino. El protagonismo de esta nueva opción para dar a luz, evidenció el deseo de sentirse activa en sus partos.
\end{abstract}

Palabras clave: Humanización; Nacimiento en casa; Protagonismo; Enfermería; Nacimiento.

\section{Introdução}

Na busca de novos rumos à humanização, o parto domiciliar, também conhecido como não intervencionista, sobressaltou-se no espaço contemporâneo, onde, por longo tempo fora realizado em comunidades, com o auxílio de parteiras e atualmente, evidenciou como uma prática a priori, planejada, nos centros urbanos, caracterizando-se uma escolha de conotação pessoal (Medeiros, Santos, \& Silva, 2008).

É importante frisar que a prática do parto domiciliar é antiga e cercada de tabus, isso, em vista da exposição da mãe e bebê a um ambiente desfavorecido de aparato médico-hospitalares. Todavia, foi por longo tempo uma prática comum, dita como normal na sociedade e, para tanto, considerado um evento fisiológico, até que no século XX, a medicina o transformasse em um evento patológico, com uma desenfreada necessidade de intervenções medicamentosas e cirúrgicas, dando ênfase a 
assistência hospitalar ao parto (Crizóstomo, Nery, \& Luz, 2007).

No Brasil, o parto domiciliar evidenciou-se como um acontecimento extravagante, que por sua vez, permaneceu aquém dos hábitos no espaço urbano contemporâneo. Foi muito comum na cidade de São Paulo, no século XX, já que o cuidado à mãe e ao bebê no domicílio era prestado de modo continuado por uma única pessoa, em geral, conhecida como a parteira (Colacioppo, Koiffman, Riesco, Schneck, \& Osava, 2010).

Contudo, as particularidades do parto domiciliar são ressaltadas com clareza e diferenciação do parto normal no ambiente hospitalar. Souza, Soares e Quitete (2014) deixam explícito que neste primeiro, há a valorização tanto da mulher, como ser protagonista, do recém-nascido, da importância do pai como sujeito do parto e da identificação da mulher com o seu ambiente, recinto, tornando-a menos ansiosa no trabalho de parto. Para Frank e Pelloso (2013) no domicílio, a mulher se torna o sujeito ativo do parto, tendo controle sobre o seu próprio corpo, atuando de forma segura, resgatando para si o próprio parto, podendo realizar suas escolhas com segurança, de forma desinibida. Além disso, Koettker, Bruggemann, Dufloth, Knobel e Monticelli (2012) apontam que o ambiente domiciliar possibilita que a mulher seja apoiada por mais de uma pessoa da sua rede social, levando a inclusão de outros filhos, quando tiver, o que, por conseguinte, favorece o vínculo familiar.

Para Medeiros et al. (2008, p. 771), o forte interesse das mulheres se reproduz quando "[...] afirmam que a escolha por um parto fora do modelo institucionalizado esteve relacionada com suas experiências vivenciadas desde o seu próprio nascimento até o momento do parto de seus filhos". Os autores revelam ainda que quanto maior o nível universitário e condição socioeconômica, maior é o acesso à informação e o tipo de assistência no processo gestacional, o que traz ainda uma reflexão sobre a grande parcela de gestantes no Brasil, que é de condição social menos favorecida e esclarecida e, por consequência, são negligenciadas pelos profissionais de saúde que, por vezes, não consideram a escolha informada um direito da mulher.

Posteriormente, Feyer, Monticelli e Knobel (2013a) reforçam a informação de que quanto maior nível de instrução acadêmica, que por sua vez garante-lhe uma renda mais estável e privilegiada de acesso à informação e serviços como plano de saúde e poder aquisitivo de contratação de profissionais de saúde, maior é o desejo de ter um parto domiciliar. Desta forma, têm acesso aos seus direitos garantidos por lei.

Todavia, para que a prática do parto domiciliar seja vivenciada de forma plena e segura, é importante adotar medidas básicas, a exemplo disso, as consultas de pré-natal com profissionais de saúde habilitados para a prestação desse serviço, cuja importância é indispensável para uma avaliação do binômio mãe-filho, seja para a prática do parto domiciliar ou hospitalar, pois é ela que pode levar segurança à mulher no processo gestacional e subsídio para uma maior autonomia na hora de escolha do parto.

As consultas de pré-natal são o ponto fundamental para a participação ativa das mães no parto domiciliar. "Este ser ativo que opta por este tipo de parto possui ou passa a ter, através do acompanhamento pré-natal, a consciência do seu papel de protagonista no parto, portanto realiza um parto ativo e espontâneo [...]" (Souza et al., 2014, p.122). Além disso, um bom acompanhamento durante a gestação resulta em taxas reduzidas de transferência hospitalar, de cirurgias cesarianas, traumas e uso de fármacos no trabalho de parto e pós-parto, que implica na redução significativa no número de cirurgias cesáreas (Sanfelice \& Shimo, 2014). No que se refere às cesárias, esse percentual está chegando a 55\% dos partos realizados no país e em alarmantes $84,6 \%$ nos serviços privados de saúde, onde se estipula que deveriam ser realizadas somente 10 a $15 \%$ dos partos totais (Brasil, 2016).

Frente ao exposto, este estudo teve como objetivo conhecer a experiência das mulheres que tiveram parto no âmbito domiciliar, nos municípios de São Luís, e São José de Ribamar, do estado do Maranhão. E especificamente descrever o perfil sociodemográfico e obstétrico das mulheres que vivenciaram o parto domiciliar; identificar fatores motivadores para vivenciar o parto domiciliar; e identificar os sentimentos vivenciados durante o parto domiciliar. 


\section{Metodologia}

Trata-se de um estudo de natureza exploratória, descritiva, com abordagem qualitativa. Que foi realizada nos municípios de São Luís, Paço e São José de Ribamar, do estado do Maranhão. Os locais das entrevistas foram designados pelas participantes, onde todas optaram por realizá-las na cidade de São Luís, sendo sete dessas entrevistas, realizadas na casa das participantes, uma em seu local de trabalho e outro em espaço público. As participantes tiveram total autonomia para a escolha do local de cada entrevista, visto a necessidade de fornecer o máximo de conforto, segurança e praticidade a cada participante da pesquisa.

Foram incluídas mulheres, maiores de 18 anos, que pariram e que fossem residentes nos municípios de São Luís, Paço do lumiar, Raposa e São José de Ribamar, do estado do Maranhão, que tiveram pelo menos um parto domiciliar, tenha sido planejado ao longo da gravidez ou ocorrido sem nenhum planejamento. Ao final, foram entrevistadas 9 mulheres. Foram excluídas as mulheres que não tiveram parto domiciliar ou que apresentassem transtornos mentais que as impedisse de responder por si mesmas.

A pesquisa teve suporte através do emprego da técnica metodológica de Snowball, conhecida como bola de neve. Albuquerque (2009) esclarece que essa técnica é uma amostra não probabilística, que é utilizada em pesquisas sociais, onde os participantes iniciais de um estudo indicam novos participantes, também conhecidos como filhos, que consequentemente, indicam novos participantes, até que seja alcançado o objetivo proposto ou o ponto de saturação.

Segundo Vinuto (2014), é uma técnica que utiliza cadeiras de referência, tornando-se útil para estudar populações difíceis de serem alcançadas, nomeando os informantes-chaves de sementes. O funcionamento e aplicabilidade dessa técnica não probabilística ocorrem através de contatos, que indicam novos contatos com características semelhantes, que permutem em sua rede social, o que implica no crescimento da amostragem, sendo favorável em pesquisas de natureza exploratória.

A coleta de dados ocorreu no período de 05 de setembro a 07 de outubro de 2017 , onde cada mulher participou de forma voluntária, ficando a critério de cada uma a escolha do dia, horário e local da entrevista. Durante a coleta, fora apresentado a aprovação da pesquisa pelo Comitê de Ética, da Universidade Federal do Maranhão (UFMA) e duas vias do Termo de Consentimento Livre e Esclarecido -TCLE, sendo assinada pela entrevistada. Uma cópia foi devolvida para a entrevistadora e outra permanecendo de posse da participante, como forma de resguardo e acesso a quaisquer esclarecimentos. Utilizou-se um gravador de voz e roteiro da entrevista semiestruturada com perguntas abertas e fechadas sobre o tema, permitindo que as mulheres se expressassem mais livremente.

Para a organização e análise dos dados, utilizou-se a técnica metodológica análise de conteúdo, que é usada para descrever e fazer a interpretação de conteúdo, que segundo Bardin (1977), se organizam em 3 polos, que são a pré-análise, que é a organização dos dados, uma sistematização inicial das ideias, que conduza a um esquema de operações de sequências para a análise. O segundo polo é a exploração do material, onde é iniciado após a anterior. É uma fase longa e estafante, que consiste na operação de codificação de todas as informações. E a fase posterior é o tratamento dos resultados, a inferência e interpretação. Nesta, os resultados brutos são tratados, de forma a tornarem significantes e válidos. A pessoa que analisa, pode adiantar interpretações de acordo com os objetivos dispostos.

Assim, após a coleta de dados, deu-se início a transcrição na íntegra de todos os áudios, através de exaustivos processos de escuta, preservando cada detalhe. Posteriormente, realizou-se a análise por meio da codificação do material, buscando classificar as informações em categorias temáticas, que nada mais é do que agrupar, organizar o conteúdo ou respostas em comuns, afim de sustentar de forma repetitiva uma informação, dando maior representatividade para que assim pudessem ser agrupados (BARDIN, 1977). Em seguida, feito a descrição desses dados e por fim a interpretação de todas as informações que compõem o trabalho.

Esta pesquisa atende à Resolução 466/12 do Conselho Nacional de Saúde (CNS) e seu início se deu somente após a 
aprovação no Comitê de Ética em Pesquisa (CEP), da UFMA, sob o Certificado de Apresentação para Apreciação Ética (CAEE) de número 66565117.0.0000.5087, e número do parecer: 2.249.369.

A identificação das participantes no decorrer do trabalho respeitou o anonimato, sendo dada pela ordem de entrevista, acompanhada da letra $\mathrm{M}$, do alfabético brasileiro, que neste contexto, está fazendo referência à palavra mulher. Sendo assim, temos: M1, M2, M3, M4, M5, M6, M7, M8 e M9.

\section{Resultados e Discussão}

Os resultados deste estudo irão inicialmente caracterizar as participantes quanto ao perfil sociodemográfico e obstétrico. Assim, temos 9 mulheres com idade mínima de 31 e a máxima de 37 anos, residentes na cidade de São Luís e apenas uma residindo na cidade de São José de Ribamar, no estado do Maranhão. Quanto ao estado civil, 3 participantes afirmaram ser solteiras, $3 \mathrm{em}$ uniões estáveis e 3 casadas. Apenas uma participante tinha uma renda familiar entre 3 e 4 salários mínimos, as demais tinham um subsídio familiar superior a 4 salários mínimos. A maioria tem ensino superior completo, com exceção de uma que afirmou ter ensino superior incompleto.

Quando questionadas se possuíam filhos, 6 delas afirmaram ter 2 filhos, 2 participantes somente 1 filho e apenas 1 informou ter 3 filhos, ou seja, 2 participantes eram primíparas, sendo as demais, multíparas. Todas afirmaram ter parido na cidade de São Luís-Ma, sendo que 3 pelo parto domiciliar planejado (M1, M3 e M5) e as demais não planejaram ter o filho em casa. Apenas uma mulher teve a experiência de ter um parto domiciliar não planejado e posteriormente planejado. Foram unânimes quanto a realização das consultas de pré-natal, com um mínimo de 7 e máximo de 12 consultas e tiveram a presença do enfermeiro obstetra no parto domiciliar.

Com finalidade de facilitar a leitura e compreensão dos resultados, estes foram organizados em três categorias temáticas, a saber: 1- Motivadores para a vivência do parto domiciliar; 2- As visões diante do parto domiciliar; 3- Emersão de sentimentos com a vivência do parto em casa.

\section{Motivadores para a vivência do parto domiciliar}

Foi possível identificar que as depoentes estimavam a humanização do nascimento, primando pela saúde e estímulo da criança e pelo o fato de querer receber seu filho da melhor forma possível, em um ambiente saudável e acolhedor. Isso foi mais claramente evidenciado pelos depoimentos das mulheres que tiveram a oportunidade de planejar o parto domiciliar, não excluindo as que não planejaram. De acordo com falas das depoentes:

Ah, então! A minha escolha pra ter o parto domiciliar foi, principalmente pra receber minha filha, que foi uma menina, da melhor forma possível, dentro de casa, no aconchego do lar e [...] então mais pela questão da humanização e pela questão do ambiente, da escolha do melhor ambiente, para recebê-la (M1).

[...] sou psicóloga infantil e desde o começo da minha carreira eu trabalhei com estimulação precoce [...] e a primeira estimulação que a criança tem é o parto, não importa como a criança nasça, tudo é estímulo. Mas o parto normal é muito melhor te dando a possibilidade de pensar na saúde mental do teu filho desde o primeiro momento (M5).

Enfim, foi isso... gostei pela questão da privacidade, de estar na minha casa com a minha família, da minha filha nascer de forma tranquila sem gente mexendo comigo e com ela (M9).

[...] pra mim ficar em casa é muito melhor e foi a melhor coisa sim, porque depois de parir, você está no seu quarto, pari no теи quarto [...] Se não tivesse favorável pra gente ter nesse ambiente, mas estando tudo favorável, ficar aqui foi uma realização mesmo (M8). 
O parto é um processo fisiológico e como tal, é um processo que denota saúde e naturalidade do corpo feminino, que tem uma necessidade e capacidade de ser alcançado sem intervenções desnecessárias. Pode se dizer que optar pelo nascimento da criança em casa é exaltar essa convicção, é vivenciar intensamente esse processo, pois o ambiente que a mulher convive diariamente acaba por ser acolhedor e confortável, transmitindo intimidade na hora de parir. Além disso, para Kruno, Silva e Trindade (2017), isso ainda revela uma insatisfação com o modelo de assistência obstétrica da rede hospitalar, dado que o planejamento do parto no domicílio exprime uma relação de desacordo com tudo que é oferecido a parturiente no trabalho de parto, tendo ela a necessidade de buscar alternativas que substituam isso e que prezem pelo respeito, saúde e estímulo do nascer.

As motivações de parir em casa, mesmo nos partos domiciliares não planejados, emergiram dessa ligação com o ambiente familiar, da estimulação precoce e saúde, além de que, o consenso entre as pessoas que estavam na casa naquele momento colaborou, facilitando o parir no ambiente domiciliar. A questão de filhos anteriores a esse processo, também foi decisiva para a permanência da depoente na sua casa, havendo uma preocupação com o recém-nascido. Houve também uma consensualidade e confiança entre a gestante e o profissional que transmitiu segurança para a chegada desse momento. Conforme as descrições abaixo:

Foi muito rápido [...], ai ela [enfermeira obstetra] disse: "Olha, você já está com nove centímetros [...], corre o risco de nascer no carro". Aí tudo que eu queria ouvir, né? As palavras mágicas, né? Nove centímetros. Eu não vou sair porque o meu filho está dormindo [...] eu não tenho com quem deixar [...] então foi meio que consensual ali de todos que estavam na casa, de que ficaríamos ali (M8).

[...] eu não queria ir para maternidade porque no momento eu tinha uma filhinha de 2 aninhos e eu não queria me separar dela, eu queria ela por perto no nascimento do irmão, então meu sonho mesmo era fazer um parto em casa e o médico me ajudou nisso ele disse que eu tinha passagem sim e que o meu filho ia nascer de forma tranquila, então tendo essa perspectiva do médico e do meu subconsciente, tudo ia acontecer para ser em casa [...] (M4).

[..] na verdade eu sempre tive o intuito de ter parto domiciliar [...] mas a minha vontade principal era de ter em casa pela confiança que eu tinha nas meninas [doulas e enfermeira obstetra] [...] (M2).

[...] a gente começou a achar que valia a pena tentar controlar o ambiente, só ter as pessoas que a gente queria no nosso parto, só ter a gente e os profissionais que a gente escolheu, uma das coisas que a gente ponderou [...] (M7).

A determinação pelo parto domiciliar, bem como sua vivência, se dá de uma forma conjunta, pelo casal e consenso entre as parturientes e profissionais envolvidos nesse processo (Feyer, Monticelli, Boehs, \& Santos, 2013b). Ao fato de poder controlar o ambiente e as pessoas presentes, as entrevistadas mostraram-se satisfeitas quanto a parir em casa, visto que foi perceptível a confiança entre envolvidos e o apoio que receberam diante deste momento. Os profissionais da saúde ajudaram a reforçar o empoderamento da mulher e do seu corpo, o que evidentemente colaborou para o grau de satisfação da parturiente e conforto das pessoas presentes no local.

É notório, pelos depoimentos, que essa escolha do domicílio tem sua implicância com relação também a presença de um filho anterior dessa mulher, ou seja, relaciona-se ao receio e desconforto de ter que abandonar seu filho a cuidados alheios aos seus e por não desejarem se separar dos filhos, devido à baixa faixa etária da criança. O que evidencia um motivo plausível e materno por optar pela permanência em sua residência, para que assim, não se rompa o vínculo afetivo e maternal com o bebê, deixando-a desprotegida de seu olhar e cuidados, mesmo que esse momento seja dedicado ao nascimento de um outro filho. Para Kitzinger (1996 como citado em Oliveira, Zampieri \& Bruggman, 2001), isso é proveniente do comportamento humano e também instintivo, pois o parto reflete nos valores pessoais de cada mulher e nas relações com o grupo familiar.

Isso confronta a realidade quanto ao âmbito hospitalar, onde se tem um rompimento de laços maternais, tendo essa mulher que abdicar de sua permanência com os filhos mais novos, quando esta possui, reforçando uma vulnerabilidade e 
preocupação com o ambiente externo, o que resulta em uma experiência ainda mais desconfortável no ambiente hospitalar, somando-se a perda do protagonismo feminino e sua submissão a mecanismos agressivos ao seu corpo. O poder estar próximo a um filho anterior na sua casa, mostrou facilitar o processo de parir, já que há uma tranquilidade e conforto em saber que ao mesmo tempo que está em trabalho de parto, essa mulher também está presente no cotidiano de seu filho, sendo responsável pelo seu cuidado e proteção quanto a qualquer ameaça, além de saber que de certa forma, essa criança está participando do nascimento do irmão.

Além desse ponto, acreditar que o parto não é um evento hospitalar, motivou as entrevistadas a parirem em casa por desejarem ter uma autonomia que não é oferecida nos modelos hospitalocêntricos atuais, assim, confrontando essa realidade. De acordo com suas falas:

\section{[...] o parto ele não é um evento hospitalar [...] (M1).}

[...] o pior é essa burocracia, "gente eu tô parindo", não me faça ter que responder perguntas (M3).

[...] eles [hospitais particulares] não gostam muito do parto normal, porque é um parto sujo, demanda mais trabalho e uma equipe diferenciada. [...] E não são todos os médicos que te dão o devido espaço no momento do parto [...] (M4).

Hospital não é um ambiente tranquilo [...] é um estabelecimento comercial [...] e eu não tava preparada pra naquele momento estar em condições de atender as regras que seriam apresentadas [...] a estrutura hospitalar não te anima a passar pelo parto (M4).

A conjuntura de parir em casa retrata uma ruptura com os modelos hospitalares de atendimento, ou seja, rompe com a assistência obstétrica oferecida nos estabelecimentos de saúde, que visa facilitar o trabalho de parto, e muitas vezes acompanhada da violência obstétrica, que emerge através dessa rotina (Sanfelice \& Shimo, 2014). Uma descontente constatação, que faz jus ao medo de muitas mulheres de serem impostas a procedimentos e comandos nas quais elas não estão de acordo, fazendo do parto um processo medicalizado, resultando em desfechos que não são favoráveis para o binômio mãefilho (Sanfelice \& Shimo, 2015).

No domicílio, a atenção é voltada para quem deve ser de direito, à parturiente, assim o profissional que for prestar serviço em outra ambiência deve se ajustar as características do local e da mulher e não ao contrário, como ocorre nos hospitais. Esta condição facilita todo um aporte emocional, de estimulação e autonomia da mulher e acaba por reduzir procedimentos desnecessários. O parto de baixo risco requer observações e isso necessita de um apoio que exige confiabilidade, respeito e sensibilidade de quem está prestando assistência (Frank \& Pelloso, 2013).

Sendo assim, o ambiente domiciliar visa se diferir da ambiência hospitalar por esse último, gerar uma intranquilidade na mulher devido toda carga de repercussão que este leva consigo. Além disso, optar pelo parto domiciliar tem uma ligação com o medo por hospitais, com o estilo de vida, a carga das más experiências que essa mulher carrega ou tem conhecimentos por terceiros. Isso é relatado nos depoimentos, quando questionado o motivo da escolha pelo parto em casa. Em suas falas:

[...] eu imagino que hospital deve ser muito assustador [...] eu fico entristecida que muitas mulheres que optam pela cirurgia elas não sentem isso, acho que elas querem é a praticidade, a velocidade, não veem pelo lado do filho também [...] (M9).

[...] primeiro eu tenho medo de hospital [...] de como é a lógica do hospital, que você chega e é, você tem que se entregar e se entregar para o seu médico, você não é mais dona do seu corpo, você não tem mais vontade, né [...] (M6). 
Eu queria porque eu não gosto do ambiente de hospital e eu li muita coisa sobre, como é que se chama? Experiências ruins no hospital, questão do desrespeito [...] e eu tava com muita dificuldade de encontrar obstetra do meu plano [...] (M9).

\section{[...] eu não consigo me imaginar tendo filho no hospital [...] (M5).}

É notório que a falta de autonomia e associação do medo de se entregar ao ambiente hospitalar emerge nas mulheres sensações que perpassam ao desejo de fuga dessa realidade hospitalocêntrica. Daí surge o desejo de serem acompanhadas por profissionais que as respeitem e acreditem no seu potencial, para que assim, flua todo o processo (Sanfelice \& Shimo, 2015). O medo de ser submetida integralmente a um ambiente e pessoas incomuns, acaba por gerar uma alteração no estilo de vida e mudança de hábitos dessas mulheres, o que consequentemente está relacionado ao momento de hospitalização e sua consequente fuga desse padrão de atendimento no momento do parto. A não concordância dos profissionais de saúde para com a subjetividade de cada mulher acaba refletindo nessa busca por alteração do local do parto.

É válido comentar, que a questão de possuir plano de saúde, faz as mulheres procurarem uma assistência particular, onde o número de cesarianas, segundo a OMS (2015) é exacerbada, sendo realizada em maior quantidade quando comparado aos hospitais públicos. E quanto a isso, a maioria das depoentes deixaram evidente em algum momento de seus depoimentos, possuírem plano de saúde, o que pode ser confirmado por uma renda salarial superior à da grande parcela populacional do Brasil.

Quanto ao local de parto, é necessário que se tenha em mente o que o MS diz a respeito às diretrizes nacionais de assistência ao parto normal, ou seja, uma atualização onde diz que cabe ao profissional de saúde informar a gestante quanto ao melhor local de parto e seus respectivos benefícios e riscos, não cabendo a ele realizar a escolha pela gestante. Além disso, informá-la que o parto domiciliar não faz parte das políticas atuais de saúde no país, sendo ele não disponível no SUS, contudo, não a desencorajando no planejamento dessa prática, que possui evidências científicas extremamente satisfatórias e baixos índices de mortalidade perinatal (Brasil, 2017).

Contudo, não somente a fuga do modelo hospitalocêntrico explanou-se como motivadores, mas também a ligação com o histórico familiar de cada mulher e o seu círculo de vivência, o que cabe salientar que o poder de decisão dessa mulher se tornou mais aflorado devido a seu núcleo de convivência. Ademais, a influência por uma experiência pessoal traumática em um parto anterior, assim como uma experiência positiva tem o poder de determinar uma influência ao vivenciar uma nova gravidez.

[...] eu já queria natural desde o começo por que minha mãe teve e a família inteira teve, é menos invasivo e a única coisa que eu sabia era que eu queria ter natural [...] (M9).

[...] é, eu tinha uma amiga que acompanhei [...] pra conseguir ter um parto humanizado e ela não conseguiu [...]. Logo que eu descobri que eu estava grávida, eu lembrei dela e já me conscientizei que eu ia ter que começar desde já a batalhar um parto do jeito que eu queria [...] (M6).

[...] deu mais vontade de ter o parto em casa, exatamente pela questão do pós-parto [...] ficamos no hospital por cinco dias [...] e esse momento foi traumático [...] (M3).

[...] então eu tinha muita confiança nelas [enfermeiras obstetras e doula], então partiu desse princípio também, porque elas acompanharam a minha primeira gestação, que foi o parto do meu filho e diante disso eu tinha muito mais confiança por conta disso, então minha vontade ela ficou mais... assim, eu fiquei com mais vontade de ter mesmo em casa, diante disso, né? (M2)

Essa construção sobre a ideia do parto em casa, tem um vínculo de simbolizações e significados com o ciclo de vida na fase reprodutiva. Essa decisão por permanecer na sua casa, assume uma postura que tem uma relação com o autocuidado, 
com a preparação, planejamento, que parte das práticas culturais ligadas a essa família, cabendo assim o respeito (Feyer, et al., 2013b).

De acordo com os depoimentos, é possível afirmar que essa prática incube uma correlação de empoderamento e força, no qual a mulher acredita no potencial do seu corpo. Uma cultura que foi transmitida por toda uma geração familiar, fazendo com que as gerações seguintes acreditassem que são capazes de passar pela mesma experiência. Sobre o cunho de convivência, a rede de amizades femininas mostrou que tem um papel influente sobre a escolha do tipo de parto, de acordo com os relatos de experiências que as amizades passaram, reforçando com que as mulheres ligadas nessa rede lutassem pela humanização, o que fora refletido por um parto diferenciado.

Quanto as experiências negativas e positivas, Medeiros et al. (2008), dizem que, vivenciar uma história de caráter negativo na experiência da maternagem, proporciona uma necessidade e desejo de querer proporcionar aos filhos posteriores um nascimento pautado na segurança e contato físico, na tentativa de suprir de algum modo o que faltou no parto anterior. Além de que, uma experiência positiva, acompanhada por bons profissionais, ajudam a determinar esse momento marcante e especial em um novo processo.

Em vista disso, é inegável que a vivência, seja ela de cunho positivo ou negativo, influencia a maneira na qual a mulher vai escolher para parir. Não é pertinente dizer que somente as experiências negativas modificam esse olhar sobre o parto, porque a positividade carrega consigo um grau de confiabilidade no potencial feminino.

\section{As visões diante do parto domiciliar}

Esta categoria teve por finalidade explorar os diferentes olhares maternos por trás do parto domiciliar. Todas as depoentes explanaram suas visões sobre a prática do parto domiciliar, evidenciando por algumas vezes um senso comum e os aspectos positivos que essa prática tem a oferecer para cada mulher. Abaixo, encontramos fragmentos que discorrem sobre a positividade dessa visão, sustentada pelo pré-natal, experiência com o pós-parto e a exaltação do ser mulher e seu instinto materno:

[...] minha visão já era bem positiva, em relação, eu acho que só tem benefícios, acho que numa gestação em que a gente sabe que é uma gestação segura, e essa questão da segurança dá pra gente prever durante todo o pré natal, né? [...] não tem por que não ser assim, em casa [...] (M1).

[...] acho que se eu tivesse um outro filho eu queria ter esse preparo pra ter em casa mesmo [...] o teu pós parto é um pós parto totalmente diferente, eu comparando o meu pós parto do meu primeiro filho com o da [filha], eu não senti nenhum mal estar [...] (M2).

Eu vejo o parto de uma maneira muito positiva, foi a coisa mais bonita que já aconteceu na minha vida, foi esse parto e antes eu tinha aquela visão que todo mundo tem, né? Que dói, que é perigoso, né? As pessoas não veem o parto como saúde, veem como doença (M6).

[...] você se vê como uma mamífera, né? Como um ser mamífero [...] então eu acho que a gente esqueceu muito dessa nossa, nosso instinto materno, instinto de mulher, de mamífera [...] (M8).

Sanfelice e Shimo (2014) afirmam uma falta da visão de naturalidade sobre o parto domiciliar, o que faz com que muitas mulheres não o vivenciem, frente ao sistema dominante hospitalar. Afirmam que parir em casa contribui para uma modificação do movimento institucional, tornando-a essa prática aos poucos despersonalizada.

Ressaltar positividade em parir em casa, confronta tudo que é passada para as mulheres atualmente. As depoentes discorrem plenamente sobre isso, sobressaltando que a segurança do pré-natal as ajudam a driblar essas adversidades. O pósparto também foi ressaltando quanto a uma visão positiva a partir do momento comparativo com a de um parto anterior. É nítida a percepção de uma corrente compostas por integrantes que querem difundir os benefícios de parir em casa, além de 
exaltar o olhar individual, para que as mulheres voltem a se ver como ser mamífero, que faz parte da natureza e possuem instintos vivos, porém desestimulados devido ao não encorajamento e desconhecimento.

Essas visões positivas sobre o processo de parto domiciliar e sua consequente adesão, não pode ser separada da condição sociocultural mais elevado, o que proporciona maiores esclarecimentos e confiança para que essa se veja como capaz até mesmo de difundir essas opiniões. Assim, a consciência sobre os benefícios está atrelada a melhores condições (Matão, Miranda, Costa, \& Borges 2017).

De certa forma, a propagação dessas visões, estão associadas por informações que são facilitadas devido suas condições socioculturais e econômicas, o que não somente sana dúvidas e as esclarecem. Essa mulher se torna um ser reflexivo, que passa a entender a realidade que se mostra paralela e passa também a questioná-la. Os trechos de depoimentos a seguir, relatam isso:

[...] a gente começou a pesquisar sobre o nascimento [...] e o primeiro grande revelador da situação foi um documentário [renascimento do parto] [...] eu comecei a estudar [...] ficava pensando: "É verdade né, eu nunca parei pra pensar nisso" e comecei a ler sobre cunho científico e tal e eu nunca pensei e fui ver, pelo que eu estudei é um problema da América Latina. [...] e eu acho que a gente precisa dessas discussões [..] (M3).

[...] não era uma teoria tão simples assim, em São Luís, no Brasil, o contexto que a gente vive ter um parto normal [...], aí eu comecei a ler, a estudar, no começo eu achei que era coisa de doidinha ter parto em casa e depois eu fui começar a ver que eu mudei e que coisa de doido é ter no hospital (M6).

\section{[...] eu pesquisei bastante, eu decidi o quê que seria feito e o quê que não seria feito [...] (M1).}

Eu já tinha antes, visto vários vídeos e estudado várias dessas questões mesmo, né? Dos riscos que poderiam ocorrer, o que não poderia ocorrer e tá me prevenindo contra isso, né? (M2).

Acessar fontes de informações diversificadas torna-as mais conscientes sobre o processo de parir em casa e é um influenciador de questionamentos, por assim, tomar consciência da situação. Aliado a condição educacional, clarifica a escolha pelo parto em casa, baseada no suporte do respeito (Lessa et al., 2014).

Ao tomarmos nota da afirmação anterior, confirma-se o elevado nível educacional relato durante as entrevistas, o que consequentemente reafirma a ligação do nível educacional, que proporciona um maior nível socioeconômico, tendo como resultante uma maior facilidade de acesso às informações disponíveis em sites, livros, revistas e demais meios de comunicações. Medeiros et al. (2008) e Feyer et al. (2013a), já haviam confirmado essa afirmação em pesquisas anteriores.

O querer discutir essa problemática no Brasil é almejar uma mudança de cenário e reforçar a garantia de acesso à informação de qualidade para todos. As depoentes mostram acreditar na necessidade de discussões, visto que creem ser um problema baseado na falta de diálogo e humanização do nascer. A informação para o parto, mostrou também a tomada de vozes das mulheres frente aos procedimentos que elas acreditavam ser necessários ou não para aquele momento, que foi abordado com a equipe, quando essa se mostrou presente, além de ser acatado, de forma a demonstrar respeito pelo conhecimento da mulher.

A visão da necessidade de informações e discussões, também foi crucial para a quebra de preconceitos com os estereótipos das mulheres que desejavam o parto domiciliar. Porém, ainda encontramos relatos que transcendem a ocorrência de uma visão intensa de dor e de irresponsabilidade antes do conhecimento dessa prática. Abaixo:

Então a visão que eu tinha do parto domiciliar, do parto natural, enfim, era que tinha dor, e eu tinha muito medo da dor e quando eu estava com 38 semanas de [referindo-se a filha] eu tinha certeza de que eu ia sentir dor, e os últimos relatos que eu tinha de parto só confirmavam isso [...] (M5). 
Logo no comecinho eu achava que era loucura, que era irresponsabilidade, que eu tava colocando o meu filho e a mim em risco, daí depois [...] eu pude desconstruir essa ideia que eu tinha e ver que o parto em casa era uma coisa saudável [...] o risco seria tanto quanto o mesmo ou até menor que se eu tivesse no hospital [...] (M6).

[...] esse negócio de parto domiciliar assim [...] olha, era coisa de gente hippie, gente muito alternativa e tal [...] (M7).

Para Souza et al. (2014), ter um parto no domicílio é aceitar que ele possui constituições e características próprias, de acordo com cada mulher, sem o seguimento de uma padronização. É um momento natural, individualizado para cada uma e que pode diferir do que esperamos. Romantizar ou esperar uma sistematização, vai além do que se deve ser aguardado.

Sobre a questão da dor, podemos extrair a partir do depoimento que ela é uma cultura difundida sobre o trabalho de parto. O que porventura, passou a ser sinônimos. Ou seja, se uma mulher está passando pelo processo gestacional, ela automaticamente vai passar pelo processo da dor, que consequentemente é vista como ruim e não como parte desse processo fisiológico que a aproxima cada vez mais do seu filho. A conotação da dor como maleficio, infelizmente transcorre difusamente a sociedade, prejudicando o entendimento do parto.

Para a discussão dos dois últimos depoimentos, Sanfelice e Shimo (2015), dizem que parir em casa não está relacionado ao modismo e que as justificativas envolvidas estão aquém do senso comum que é propagado. São apenas mulheres que possuem o desejo de poder resgatar o protagonismo, objetivando uma vivência plena, prazerosa e bela (Sanfelice \& Shimo, 2014).

Não é difícil ouvir que o parto domiciliar está associado a um seguimento de moda, ou como um ato impensado, irresponsável e de risco, no qual a mulher não está nenhum pouco preocupada com a saúde do seu filho. O que nos leva a refletir no quão incômodo e necessário é essa discussão, até porque essa era a visão até mesmo de algumas depoentes antes de passar por essa experiência, e que requer leituras científicas para sanar tais questionamentos.

Além disso, foi possível perceber que a visão sobre o parto domiciliar, perpassa o direito de escolha e a importância de dividir esse momento com pessoas que as apoiem e incentivem, as tornaram mais confiantes e seguras. Escolher as pessoas que fariam ou não parte do trabalho de parto também se mostrou favorável, por estar relacionado a ligação íntima entre esses. O apoio familiar demonstrou-se gratificante para essas mulheres. Porém, esse apoio não foi comum para todas as depoentes. Abaixo:

[...] eu escolhi as pessoas que estavam lá comigo, é, eu escolhi as que não deveriam estar, né? [...] a mãe escolhe o que ela quer, não cabe aos outros opinar [...] o pai é super a favor, sempre foi, mais do que eu, antes do que eu ele já era, e a minha mãe, e todo mundo assim apoiou (M1).

[...] estar próximo da família, acho que isso é mais gratificante impossível, porque tá toda a tua família ali e no hospital a gente não tem isso, né? Você tem que escolher uma pessoa da família [...] (M2).

[...] estavam na minha casa de visita a minha mãe e a minha sogra e a gente já tinha combinado que elas não estariam, justamente por elas não terem passado por essa educação e minha mãe muito dramática, poderia fazer comentários indesejados [...] (M3).

[...] não tinha o apoio da minha família [...] minha mãe não me apoiava, então ela, eu menti pra ela o dia que ele ia nascer $[\ldots]($ M6).

Para Kruno et al. (2017), de antemão, a família demonstrar um certo temor diante da opção do parto que é relatado a eles, é visto como normal, ou seja, comum por ser um processo novo. Já são esperados questionamentos e dúvidas sobre essa decisão. 
Além disso, a importância da família nesse momento é evidente de modo a configurar um núcleo de tranquilidade e segurança. A presença do pai e consequentemente seu apoio, é imprescindível, por emergir uma positividade e a partir daí, criar laços de envolvimento e reponsabilidade com o bebê que está a nascer (Frank \& Pelloso, 2013).

Foi perceptível que essas depoentes fizeram valer seu direito de escolha e não almejaram a presença de familiares que as confrontaram diante suas escolhas pessoais de vivenciar o parto domiciliar. Por mais que se tenha uma ligação de mãe-filha, o mais plausível foi retirá-las desse momento, permanecendo essas mulheres donas de suas escolhas, optando por passá-las ao lado de quem realmente as apoiassem e transpassavam segurança.

A demonstração de satisfação pela vivência do seu direito de escolha em um ambiente acolhedor e familiar, cercado por pessoas especiais para essa mulher, é um modo de obter autonomia e libertação sobre tudo que lhe é dito para fazer em suas vidas (Medeiros et al., 2008).

Essas mulheres reestabelecem boas bases de vínculos sociais e familiares, o que fortalece o relacionamento interrelacional. Através desse empoderamento de escolhas, seu potencial é maximizado e consolidado por sua opção e decisão (Lessa et al., 2014).

\section{A emersão de sentimentos com a vivência do parto em casa}

A última categoria temática deste estudo visa descrever todos os sentimentos vivenciados pela mulher no parto domiciliar. A eclosão de sentimentos e sensações, demonstram a forma visceral e límpida de como esse parto foi sentido por cada uma das depoentes. Sentimentos que perpassam o se sentir ativa, a grandiosidade do parir, realização, a libertação com todas as imposições, o alívio, amor e felicidade, foram alguns dos sentimentos discorridos por elas. Veja abaixo:

A gente vivencia, a gente é ativo não é passivo, não são os profissionais que vão fazer o bebê nascer, é a gente que faz, né? [...] foram os melhores sentimentos assim, com certeza é uma experiência que se eu pudesse escolher, eu passaria várias vezes na minha vida, porque é maravilhoso (M1).

Gente, é um sentimento que só mesmo acho que quem é mãe pra saber [...] é um sentimento assim grandioso [...] é o melhor sentimento que acontece na vida de uma mulher [...] uma realização, inexplicável mesmo, sabe? É um sentimento muito bom (M2).

[..] momento de libertação, que eu tinha que aceitar aquela situação, tinha que resolver e aceitar, gerenciar tudo (M4).

Eu fiquei muito feliz de ter dado tudo certo no final, porque a gente não tinha se organizado pra isso [...] alívio, fora a felicidade que a gente ficou, foi o alivio [...] (M7).

Amor, conforto, conforto não é um sentimento, mas eu digo que é amor, amor, segurança, acho que foi o ambiente mais seguro [...] (M8).

A mulher supera-se, demonstra que é ativa e capaz de conquistar todo esse protagonismo. Sente que rompe com a ideia de fragilidade, submissão e incapacidade, transfigurando assim seu apogeu feminino. Tem um sentimento de prazer com todo o ocorrido no seu parto, ficando fortalecida para enfrentar outras situações parecidas (Castro, 2014).

Para as depoentes, essa vivencia foi única e seu entendimento é facilitado por quem passou por algo similar. A significância da grandiosidade do ser mãe e libertação com todas as burocracias hospitalares, mostrou ser resultado dessa quebra da hegemonia hospitalocêntrica. Além disso, os sentimentos de alívio, amor e felicidade esteve presente na vivencia dessas depoentes durante o parto domiciliar. Um alívio que pode ser interpretado tanto pelo nascimento do filho, quanto por permanecer no conforto do seu lar. Os sentimentos de amor e felicidade estão relacionados ao momento que essas mulheres puderam ter em seus braços aquele bebê tão sonhado, podendo assim, ter a certeza da concretização desse instante. 
Além disso, foi observado o sentimento de empoderamento, exaltado por algumas mulheres, por acreditarem estar incumbindo empoderamento aos filhos, facilitando a aceitação para com o irmão, quando está constituição fora formado por uma prole feminina, além do sentimento de reconhecimento com o bebê que está em seu braço. Abaixo:

[...] a minha filha sabe que o bebê veio da barriga [...] ela nunca vai cair em história [...] isso de saber a verdade já empodera ela, de saber que foi a minha mãe e não médico que me deu a minha irmã (M3).

[...] aí a minha filhinha pegou na minha perna e disse: "Mamãe não chora, vai passar", [...] e aí ela viu o neném que tinha acabado de nascer, viu que ele não estava na minha barriga [...] (M4).

[...] o [referindo-se ao filho] viu o irmão nascer [...] não é todo irmão que vê o irmão nascer [...] acolher esse irmão foi muito mais fácil do que eu acho que se eu tivesse ido pro hospital e chegado aqui, né? "Opa! Mamãe foi e voltou com esse bebezinho no colo", então acho que até pro entendimento dele foi assim, bem melhor ter nascido em casa (M8).

[...] um sentimento de espanto, você não acredita que fez aquele ser humano e ela mexe e ela pisca e ela chora e a gente se reconhece naquele momento, eu como mãe e ela como filha [...] (M5).

Para Castro (2014), compartilhar esse sentimento de empoderamento reforça a força da figura feminina. É sentir-se capaz e orgulhosa por cuidar dos filhos e ao mesmo tempo de si. Ao mesmo tempo que a palavra representa tanta força e vitalidade, ela revela uma simplicidade, por emergir de uma vivência tão natural, de natureza e manifestação própria do seu corpo.

Em relação ao nascimento e empoderamento, Odent (2002) diz que, essa informação entre mãe e filho é valiosa, pois é uma experiência e conhecimento eficazes para a vida, contudo que está em decadência devido as intervenções no parto.

É notório que essa relação de empoderamento acaba por gerar uma facilitação da aceitação entre irmãos, sobressaltando a figura materna como responsável por tudo aquilo que é visto naquele momento. Não excluindo o empoderamento dos filhos que vislumbram esse acontecimento com naturalidade e com o poder de propagar essa natureza para a vida adulta, podendo torná-los além de empoderados, seres humanos cientes dos processos fisiológicos humanos.

Por fim, foi relatado o sentimento de conexão. Não somente conexão para com o filho que estava nascendo, mas uma conexão além de tudo aquilo que se é esperado. Os relatos abaixo perpassam uma conexão com o mundo, uma divindade e o próprio "eu" interior. Veja:

\section{[...] é uma conexão com o mundo [...] foi revigorante, dá esperança e vontade de parir de novo (M3).}

[...] conexão com o divino, daquilo que a gente não entende, né? [...] eu achava que eu conhecia o mundo. Com certeza ali tinha Deus, alguma coisa parecida, né? [...] o parto em si, me fez acreditar no bem, nas pessoas, no milagre, na natureza, nо теи согрo [...] (M6).

[...] a sensação foi de conexão, eu senti que eu tinha uma família a partir dali [...] parece que eu me tornei uma pessoa mais competente depois do parto (M9).

Esses relatos de sentimento de conexão, podem ser interpretados como o momento do nascimento do filho, a ligação ainda com o cordão umbilical e o estar aconchegado ao seio materno. Sentir-se conectada ao mundo, ao universo, exprime um sentimentalismo primitivo, despida de qualquer artifício ou facilitador para o parto. É a vivência límpida da natureza do mundo, do ser mulher, do protagonismo do papel que lhe foi incumbindo pela natureza. Além de que, é a formação de novos laços e prosseguimentos familiares, uma conexão que perpassa o entendimento humano. 


\section{Considerações Finais}

O presente estudo alcançou todos os objetivos propostos, foi possível observar que fatores como, idade, renda familiar e grau de escolaridade, foram pontos decisivos para a escolha pelo parto domiciliar, visto que, essas mulheres detinham um maior grau de conhecimento e um nível de formação que sustentava a sua renda familiar, que a priori, é superior à da média populacional. Além disso, tiveram acesso as consultas de pré-natal, o que possibilitou ter um respaldo para que fundamentassem suas escolhas.

Aos aspectos motivacionais pela escolha do parto domiciliar, foi perceptível que, a estimação pela humanização do nascimento, a ambiência acolhedora de casa, a preocupação com filhos anteriores, a confiança para com os profissionais, o não acreditar no parto como evento institucionalizado e as experiências de mulheres com vínculos próximos, foram exaltadas como motivadores para essa vivência, fazendo disso, o alicerce sustentador desse desejo por parir em casa, da vivência visceral e límpida da fisiologia do parir e de se sentirem ativas e protagonistas do seu parto.

Em meio aos sentimentos que surgiram no momento da vivência do parto domiciliar, ficou claro a emersão de sentimentos como o amor, alívio, felicidade, conexão, realização, libertação para com todas as imposições, o empoderamento dos filhos mais novos e reconhecimento para com o seu bebê, o que possibilitou mensurar a grandiosidade da satisfação pela autonomia da escolha por esse modo de parir. Esses sentimentos foram resultantes de uma experiência despida de controles, prevalecendo uma harmonia para com seu corpo e o momento do parto.

O poder vivenciar essa experiência, revelou um rompimento com a indústria hospitalocêntrica e um confrontamento com o que se é oferecido pelos sistemas de saúde, seja esse de âmbito público ou privado. A necessidade dessa vivência do parto em casa, trouxe para elas, uma maior confiabilidade em seus corpos e na sua capacidade de parir, tornando-as mulheres que têm a certeza que são as únicas responsáveis pelo seu protagonismo no parto. $\mathrm{Na}$ área da saúde, o enfermeiro obstetra mostrou-se como figura presente e colaborativa durante o parto domiciliar, permanecendo durante o trabalho de parto, de forma a passar segurança para essas mulheres. E assim, evidenciando a sua capacidade profissional de fornecer um respaldo e segurança para passagem dessa experiência.

Esse estudo apresenta limitações, como o fato de ter um público participante reduzido de apenas 9 mulheres, o fato de não ter consigo encontrar mulheres de dois municípios listados nos objetivos dessa pesquisa e talvez pela escolha da técnica para que se chegasse a essas mulheres, visto que o ciclo social pode ter influência, deixando a parte, mulheres de classes econômicas menos favorecidas. É visto a necessidade de sugerir outros estudos, em outros estados e municípios brasileiros, para confrontação dos resultados e melhor compreensão desse movimento que busca pela humanização do parto.

\section{Referências}

Albuquerque, E. M. (2009). Avaliação da técnica de amostragem “respondent-driven sampling” na estimação de prevalências de doenças transmissíveis em populações organizadas em redes complexas (Dissertação de Mestrado). Fundação Oswaldo Cruz, Escola Nacional de Saúde Pública Sérgio

Bardin, L. (1977). Análise de conteúdo. Edições 70 Ltda.

Brasil. (2016). Ministério lança protocolo com diretrizes para parto cesariana. Brasília: Autor. Recuperado de https://www.unasus.gov.br/noticia/ministeriolanca-protocolo-com-diretrizes-para-parto-cesariana.

Brasil. (2017). Diretrizes nacionais de assistência ao parto normal: versão resumida. Autor. https://bvsms.saude.gov.br/bvs/publicacoes/diretrizes_nacionais_assistencia_parto_normal.pdf.

Castro, M. R. (2014). Ressignificando-se como mulher na experiência do parto: experiência de participantes de movimentos sociais pela humanização do parto (Tese de doutorado). Escola de Enfermagem da Universidade de São Paulo, São Paulo, SP, Brasil.

Colacioppo, P. M., Koiffman, M. D., Riesco, M. L. G., Schneck, C. A., \& Osava, R. H. (2010). Parto domiciliar planejado: resultados maternos e neonatais. Revista de Enfermagem Referência, 3(2), 81-90.

Crizóstomo, C.D., Nery, I.S., \& Luz, M.H.B. (2007). A vivência de mulheres no parto domiciliar e hospitalar. Escola Anna Nery, 11(1), 98-104. 
Research, Society and Development, v. 10, n. 7, e53710716684, 2021

(CC BY 4.0) | ISSN 2525-3409 | DOI: http://dx.doi.org/10.33448/rsd-v10i7.16684

Feyer, I. S. S., Monticelli, M., Boehs, A. E., \& Santos, E. K. A. (2013b). Rituais de cuidado realizados pelas famílias na preparação para a vivência do parto domiciliar planejado. Rev Bras Enferm., 66(6), 879-886.

Feyer, I. S. S., Monticelli, M., \& Knobel, R. (2013a). Perfil de casais que optam pelo parto domiciliar assistido por enfermeiras obstétricas. Escola Anna Nery, 17(2), 298-305.

Frank, T. C., \& Pelloso, S. M. (2013). A percepção dos profissionais sobre a assistência ao parto domiciliar planejado. Revista Gaúcha de Enfermagem, (34), $1,22-29$.

Koettker, J. G., Bruggemann, O. M., Dufloth, R. M., Knobel, R., \& Monticelli, M. (2012). Resultado de partos domiciliares atendidos por enfermeiras de 2005 a 2009 em Florianópolis, SC. Revista de Saúde Pública, 46(4), 747-750.

Kruno, R. B., Silva, T. O., \& Trindade, P. T. O. (2017). A vivência de mulheres no parto domiciliar planejado. Revista Saúde UFSM, 43(1), 22-30.

Matão, M. E. L., Miranda, D. B., Costa, B. P., \& Borges, T. P. (2016). A visão médica do parto domiciliar: factível ou utópico? Revista. Enfermagem. Cent. Oeste, 6(2), 2147-2155.

Medeiros, R. M. K., Santos, I. M. M., \& Silva, L. R. (2008). A escolha pelo parto domiciliar: história de vida das mulheres que vivenciaram esta experiência. Esc. Anna Nery, 12(4), 765-772.

Organização Mundial da Saúde. (2015). Declaração da OMS sobre taxas de cesáreas. Genebra: Autor. http://apps.who.int/iris/bitstream/10665/161442/3/WHO_RHR_15.02_por.pdf.

Sanfelice, C. F. O., \& Shimo, A. K. K. (2014). Parto domiciliar: avanço ou retrocesso? Revista Gaúcha de Enfermagem, 35(1), 157-160.

Sanfelice, C. F. O., \& Shimo, A. K. K. (2015). Parto domiciliar: compreendendo os motivos dessa escolha. Texto Contexto Enfermagem, 24(3), 875-882.

Souza, R. M., Soares, L. S., \& Quitete, J. B. (2014). Parto natural domiciliar: um poder da natureza feminina e um desafio para a enfermagem obstétrica. Revista de pesquisa Cuidado é fundamental online, 6(1), 118-131.

Vinuto, J. (2014). Amostragem em bola de neve na pesquisa qualitativa: um debate aberto. Temáticas, 22(44), 203-220. 